\title{
Sialendoscopy for Improvement of Salivary Flow in Patients with Sjögren Syndrome - Comparative Analysis of Intraglandular Washing Solutions
}

\author{
Gabriela Robaskewicz Pascoto ${ }^{10}$ Andrese Aline Gasparin ${ }^{2(0)}$ Otávio Bejzman Piltcher ${ }^{10}$ \\ Gabriel Kuhl ${ }^{10}$ Leandro Totti Cavazzola ${ }^{3}$ (1)
}

${ }^{1}$ Department of Otorhinolaryngology, Hospital de Clínicas de Porto Alegre (HCPA), Porto Alegre, RS, Brazil

${ }^{2}$ Department of Reumatology, Hospital de Clínicas de Porto Alegre (HCPA), Porto Alegre, RS, Brazil

3 Department of General Surgery, Hospital de Clínicas de Porto Alegre

Address for correspondence Gabriela Robaskewicz Pascoto, MD, Departamento de Otorrinolaringologia, Clínica AVITA Medicina, Rua Dom Jaime Câmara, 66, sala 401, Centro, Florianópolis, SC, 88015-120, Brazil (e-mail: gabrielapascoto@gmail.com).

(HCPA), Porto Alegre, RS, Brazil

Int Arch Otorhinolaryngol 2021;25(1):e6-e11.

\begin{abstract}
Keywords

- salivary flow

- Sjögren syndrome

- sialendoscopy

- salivation

- parotids

Introduction Among the potential diseases that present altered salivary flow and activity is Sjögren syndrome. Sialendoscopy seems to be an important therapeutic option.

Objective To compare the results obtained with sialendoscopy for improving salivary flow measured by scintigraphy in patients with primary Sjögren syndrome to those obtained with other intraglandular washing solutions.

Methods Patients from our institution's rheumatology clinic diagnosed with primary Sjögren syndrome underwent parotid scintigraphy prior to the sialendoscopy procedure. During the sialendoscopy procedure, one of the parotid glands was randomized to receive a wash with saline while the other was washed with a corticosteroid solution. After 1 month, a new scintigraphy examination of the parotid glands was performed to observe the salivary flow for comparison.

Results A total of 13 female patients with mean age of 53.38 years (range, 27-76 years) were included in this study. After sialendoscopy, 10 patients (76.92\%) were observed to have improvement in salivary excretion with radiopharmaceutical during scintigraphy. When analyzing each gland that was treated separately (26 glands), after sialendoscopy, improvement was observed in 18 glands (69.23\%), 8 treated with dexamethasone and 10 with saline solution in the wash. There was no improvement in 8 glands (30.77\%).

Conclusion This study demonstrates that sialendoscopy is as an important tool to improve salivary flow measured by scintigraphy in patients with primary Sjogren syndrome, increasing salivary excretion through dilation and consequent unblocking of the ducts. These data suggest that there is no statistically significant difference between intraductal washing solutions using saline or dexamethasone solution.
\end{abstract}

received

April 29, 2020

accepted

July 29, 2020

published online

September 30, 2020
DOI https://doi.org/ $10.1055 / \mathrm{s}-0040-1716574$. ISSN 1809-9777.

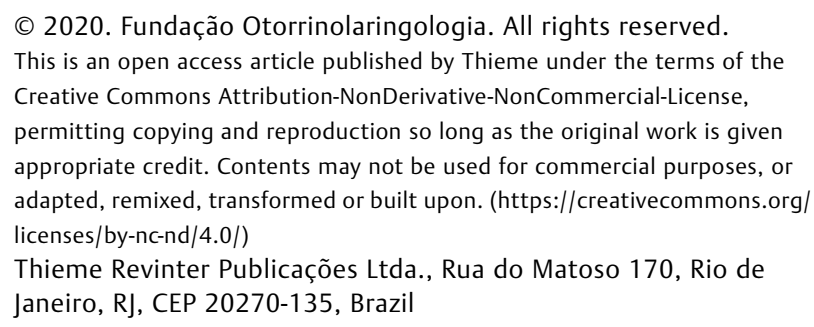

(c) 2020. Fundação Otorrinolaringologia. All rights reserved. This is an open access article published by Thieme under the terms of the Creative Commons Attribution-NonDerivative-NonCommercial-License, permitting copying and reproduction so long as the original work is given appropriate credit. Contents may not be used for commercial purposes, or adapted, remixed, transformed or built upon. (https://creativecommons.org/ licenses/by-nc-nd/4.0/) Thieme Revinter Publicações Ltda., Rua do Matoso 170, Rio de Janeiro, RJ, CEP 20270-135, Brazil 


\section{Introduction}

The word xerostomy comes from the Greek xeros, which means dry, and stoma, that is, mouth; thus, the term is used to define dry mouth. This term refers to a sensation of decreased salivation, with disease and medication sideeffect as its main causes. ${ }^{1,2}$ Studies show that $\sim 30 \%$ of the world's population reports some degree of dry mouth, ${ }^{1}$ reaching more than $60 \%$ in the elderly population. ${ }^{3,4}$ Insufficient salivary flow results in important oral effects: difficulty in preparing the bolus, reduced taste, increased susceptibility to oral diseases, ${ }^{1}$ and difficulty while talking without frequent fluid intake. ${ }^{5}$

Among the potential diseases that present altered salivary flow and activity is Sjögren syndrome. Sjögren syndrome is a slowly progressive autoimmune disease, characterized by lymphocytic infiltration of the exocrine glands, resulting in xerostomy and sicca keratoconjunctivitis. ${ }^{5}$ It occurs mostly in females and typically begins between the $4^{\text {th }}$ and $6^{\text {th }}$ decades of life. ${ }^{6}$ It is called primary when it occurs in isolation. It may also be associated with other rheumatological diseases, such as rheumatoid arthritis, scleroderma, and systemic lupus erythematosus. When associated with such diseases, it is called secondary Sjögren syndrome.

Among the salivary glands, the parotid gland is frequently affected by Sjögren syndrome. ${ }^{6}$ Using sialendoscopy, it was observed that the major cause of recurrent sialadenitis in patients with autoimmune diseases is stenosis. ${ }^{6}$ Because Sjögren syndrome affects the flow and production of saliva, strictures (due to chronic inflammation), debris, and calculations are frequent findings. ${ }^{6-8}$

Since the medications that are used to control Sjögren syndrome do not maintain function and do not predict recurrent infection of the salivary glands, ${ }^{6}$ sialendoscopy is an important therapeutic option. The sialendoscopy exam can analyze in a broad way the major salivary glands, including the parotid and submandibular. In addition to diagnosing, it can be used as a treatment. The concept of sialendoscopy has been known for 30 years, being first described in 1990 by Katz. ${ }^{9}$ Initially used for diagnosis, today it plays an important role both in the diagnosis and treatment of calculi and strictures of salivary gland ducts. ${ }^{9}$

Many therapeutic modalities exist, and they include duct washes with corticosteroids, collecting baskets (wire baskets) for calculi, ductal balloon dilation, and laser lithotripsy. ${ }^{10}$ Sialendoscopy significantly decreases the duration of hospital stays and cost of treating non-tumoral salivary diseases. ${ }^{11}$ Although sialendoscopy is widespread in Europe and North America, the knowledge and consequent use of this modality is still minimal in Latin America. We sought to compare the results obtained with sialendoscopy to improve salivary flow, measured by scintigraphy of the parotid glands, and to compare the salivary flow measured by scintigraphy after washing the parotid glands with saline versus hydrocortisone. A secondary objective was to describe common endoscopic findings in the parotid glands affected by Sjögren syndrome.

\section{Methods}

\section{Study Design}

Patients from the rheumatology outpatient clinic of Hospital de Clínicas de Porto Alegre (HCPA) diagnosed with primary Sjögren syndrome were invited to participate in the study between May and December 2015. Written informed consent was obtained. Inclusion criteria included: patients of both genders, aged > 18 years, who had received treatment from the HCPA rheumatology outpatient clinic for an established diagnosis of primary Sjogren syndrome. Exclusion criteria included: lack of regular follow-up at the HCPA rheumatology clinic, no established diagnosis of Sjogren syndrome, or refusal to participate in the study.

The patients who matched the inclusion criteria were submitted to scintigraphy of both parotids prior to sialendoscopy. During sialendoscopy, one of the parotid glands was washed with saline ( $0.9 \%$ saline) and the other with $4 \mathrm{mg}$ of dexamethasone solution through predetermined doubleblind randomization. One month after the procedure, a new scintigraphy examination of the parotid glands was performed to observe the salivary flow of both glands for comparison.

The calculation for simple randomization was provided by the randomization software sealed envelope (Sealed Envelope Ltd, London, UK), and the list created is in -Appendix 1 Available online. This was a double-blind study, since neither participants nor researchers knew which side was "case" and which one was "control." The sequence generated by the randomization method specified sides "A" and "B," and the person in charge of the pharmacy sector at HCPA decided which one would be "right" and "left."

Once this decision was made, the medications came ready and filled from the pharmacy with the marking "R" and "L," with one being the physiological solution and the other being the solution with $4 \mathrm{mg}$ of dexamethasone.

\section{Dynamic Scintigraphy of Salivary Glands}

All tests were performed at the Nuclear Medicine Center of the HCPA using two equivalent devices in the operation and acquisition of results. Each exam lasted 40 minutes and started with the patient already under the chamber with peripheral venous access ready to receive the radiopharmaceutical Tc-99m pertechnetate (radiation index of $10 \mathrm{mCi}$ or $370 \mathrm{MBq}$ ). The acquisition curves started before the intravenous application of the radiopharmaceutical and continued for 30 minutes with a temporal resolution of 15 seconds. This was the moment of capture and excretion without stimulation. Then, the patient was offered $10 \mathrm{ml}$ of lemon juice (citrus stimulus), and another 10 minutes of curve acquisition was performed. A 120-point curve was generated (curve of 120 images of 15 seconds each, with a matrix of $64 \times 64 \times 8$ and a zoom of 1.2 ). The same computer processed all tests.

\section{Scintigraphy Results Interpretation}

The scintigraphy exam of each patient generated a curve according to the glandular activity and the elapsed time. This 
8 Sialendoscopy for Improvement of Salivary Flow in Patients with Sjögren Syndrome Pascoto et al.

curve is divided into two phases: SLOPE UP, which corresponds to the accumulation of the radiopharmaceutical Tc$99 \mathrm{~m}$ pertechnetate in the glandular parenchyma; and SLOPE DOWN, which corresponds to the excretion phase. The second phase begins with the administration of citrus juice ( $10 \mathrm{ml}$ of lemon juice), which generates the elimination of the radiopharmaceutical into the oral cavity, informing the patency of the parotid salivary ducts and the functional integrity of the gland as a whole. ${ }^{12,13}$

The values of SLOPE UP and SLOPE DOWN are expressed in values that correspond to the accumulation of the radiopharmaceutical by time in seconds. ${ }^{12,13}$ In the present study, the improvement values in SLOPE DOWN are important, as sialendoscopy acts by trying to unblock the passage for saliva elimination

\section{Procedure (Intervention)-Sialendoscopy}

The same otolaryngologist doctor performed all tests at the otorhinolaryngology ambulatory of HCPA. The tests were recorded and a sialendoscopy questionnaire was completed (-Appendix 2 - Available online).

An initial preparation with cotton soaked in $10 \%$ xylocaine spray was placed over the left Stensen duct papilla. After 1 minute, local anesthesia was applied to the mucosa with $0.3 \mathrm{ml}$ of $2 \%$ xylocaine without vasoconstrictor, in a region close to Stensen duct. While the medication was acting, a mouth opener was positioned on the right side for greater comfort of the patient during the procedure. While sialendoscopy was being performed, a mouth aspirator was used to suck the produced saliva when necessary.

Initially, papilla dilators were inserted with a gradual increase in diameter to dilate the entrance of the endoscope. After insertion of the endoscope, $9 \mathrm{ml}$ of $2 \%$ xylocaine without vasoconstrictor were used for duct anesthesia. Saline solution was used for the remainder of the procedure, never exceeding $30 \mathrm{ml}$. At the end of the procedure, the preestablished randomized solution was used for each gland of each patient-either with $1 \mathrm{ml}$ of saline solution (control group), or with $1 \mathrm{ml}$ of solution containing $4 \mathrm{mg}$ of dexamethasone (case group). The same procedure was repeated on the right side.

During sialendoscopy, the objectives were to remove mucus plugs, stenoses, or stones that were obstructing the passage and exit of saliva. For this, appropriate material was used, depending on each case (balloons for expansion, baskets or tweezers for removal of stones).

At the end of the procedure, there may have been a need to fix the drain on the papilla using polypropylene 6.0 suture thread (Ethicon, Inc., Bridgewater, NJ, USA), depending on the examination and diagnosed pathology, a decision that was made by the otorhinolaryngologist during the examination. This drain, if used, was removed in one week, at the time of the first consultation after the procedure.

All patients were treated with antibiotic therapy with amoxicillin $875 \mathrm{mg}$ + clavulanic acid $125 \mathrm{mg}-12 / 12$ hours for 10 days. In the case of drug allergy, clindamycin $300 \mathrm{mg}-$ $8 / 8$ hours for 10 days was used. The treatment aimed to cover anaerobic bacteria, preventing any chance of infection after the procedure. If the patient experienced pain, dipyrone 500 $\mathrm{mg}-6 / 6$ hours was also prescribed (paracetamol $500 \mathrm{mg}-$ $6 / 6$ hours in case of allergy). Local cold compresses during the first 2 days were used. Guidance was provided to avoid acidic foods that increase salivary production during the first week, preventing discomfort during this period. ${ }^{14}$

\section{Standardization of the Classification of Abnormalities} The classification of salivary obstructive abnormalities published by Marchal et al (2009) ${ }^{11}$ was used.

\section{Material Supply and Maintenance}

Karl Storz SE \& Co. KG (Tuttlingen, Germany) provided the necessary equipment to carry out the sialendoscopy tests and procedures, the video set for filming, and recording of the procedures (Appendix 3). H. Strattner \& Cia Ltda (Rio de Janeiro, RJ, Brazil) provided the necessary maintenance during the study.

\section{Statistical Analyses}

After data collection, the McNemar test was used for paired analyses, which assessed the efficiency of "before" and "after" situations. Measurement on a nominal scale was used to assess changes in the "after" situation in relation to the "before" situation.

\section{Budget}

A request was made to Fundação de Ensino e Pesquisas Econômicas (FIPE)- HCPA for covering the costs of scintigraphy examination of parotid glands for each patient, syringes of 1 and 10-ml capacity, sutures, needles, gauze, cotton, medications used, expenses for sterilizing materials, gloves for procedures, masks, disposable laboratory coats, disposable vacuum hoses, printing of questionnaires, folders, and pens.

\section{Results}

Eighteen female patients provided written informed consent. Among these, 5 did not complete the study: 2 patients refused to undergo scintigraphy of the parotid glands; 1 patient underwent the first scintigraphy, presented with panic symptoms during the procedure, and withdrew consent; in 1 patient, it was not possible to catheterize the right parotid papillae, making it impossible to follow-up and compare the sides; and in 1 patient, it was not possible to catheterize any of the parotid papillae, thus preventing the segment and before and after comparison.

Thirteen female patients completed the research with a mean age of 53.38 years (range, 27-76 years). All patients had an initial scintigraphy with compatible findings of Sjögren syndrome, in which both glandular absorption and radiopharmaceutical excretion were reduced. In all 13 patients, sialendoscopy was successful without complications during or after the procedure. All patients were discharged home immediately after the procedure was completed. All patients completed treatment with antibiotics for 10 days and used analgesics if necessary. 


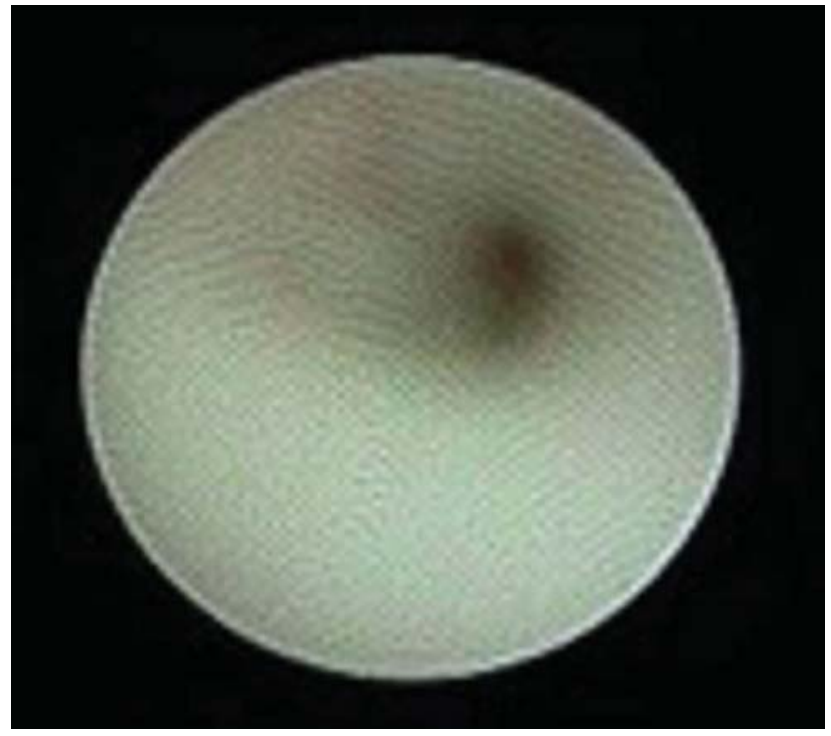

Fig. 1 Major stenosis in the main duct of the parotid gland visualized during sialendoscopy.

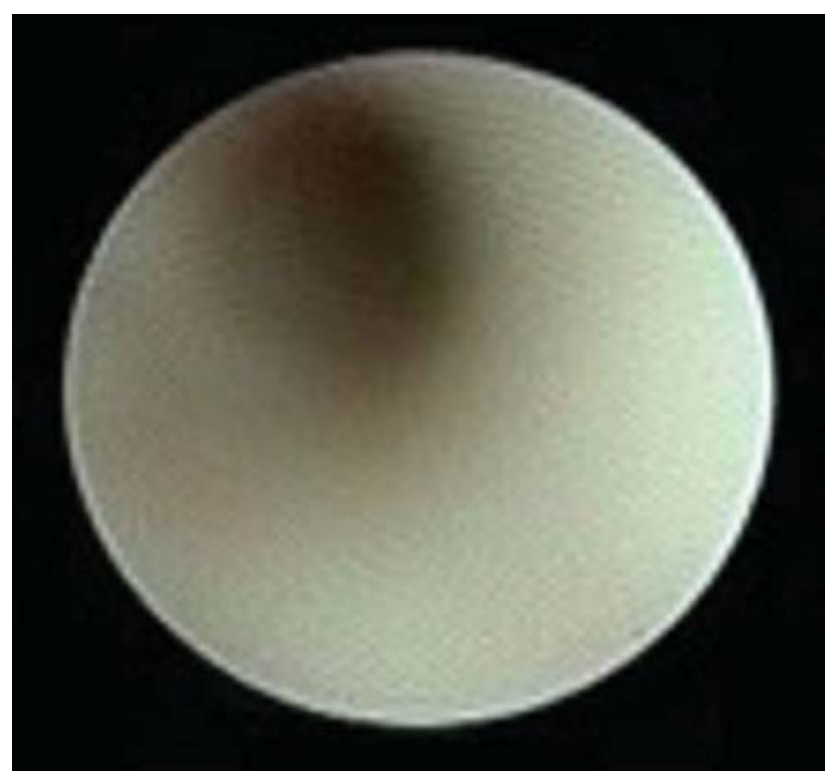

Fig. 2 Stenosis (other) in the main duct of the parotid gland visualized during sialendoscopy.

During sialendoscopy, all patients presented with an aspect of the duct mucosa classified as S4 by Marchal, ${ }^{11}$ in which there is global narrowing of the ducts with the appearance of pale scar tissue; and L0, in which no calculi were found (-Figs. 1 and 2; - Fig. $\mathbf{3}$ for comparison).

There was improvement in salivary excretion with radiopharmaceutical in the scintigraphy examination (SLOPE DOWN). After sialendoscopy, improvement was seen in 10 patients, making up $76.92 \%$ of the sample. In analyzing each treated gland separately, (26 glands), there was improvement after sialendoscopy in 18 glands (69.23\%), and no improvement in 8 glands (30.77\%).

In the comparative analysis between the glands washed with physiological solution and the glands washed with dexamethasone $4 \mathrm{mg}$, there was improvement in 10 of the

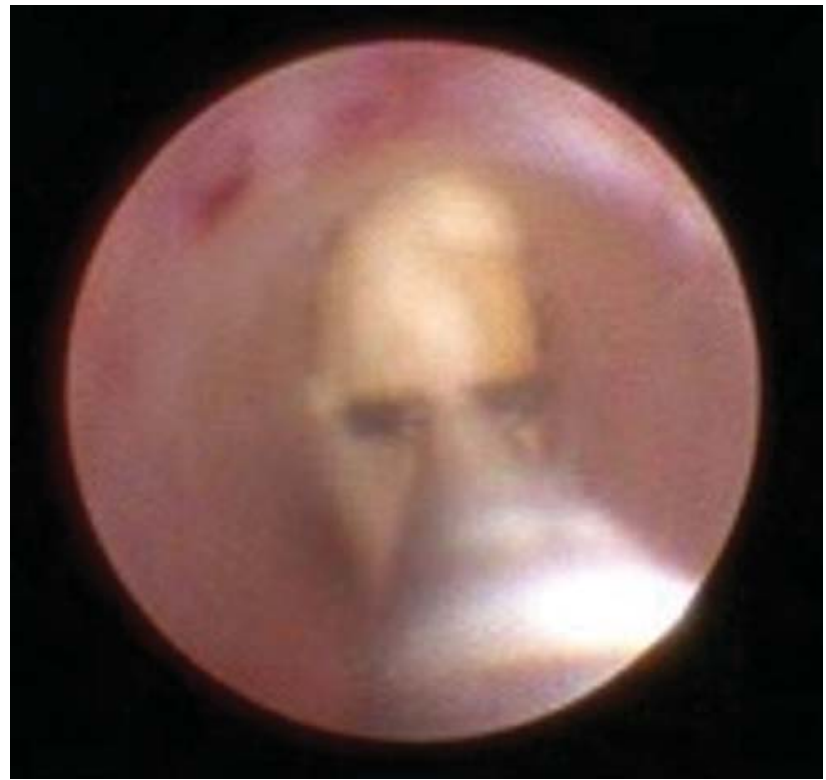

Fig. 3 Example of a duct with normal diameter, where it is possible to introduce and manipulate with tweezers. In this case, calculation of the salivary gland in the main duct being removed by forceps. Author's personal file.

Table 1 Fisher exact test results

\begin{tabular}{|l|l|l|l|}
\hline & Improvement & $\begin{array}{l}\text { No } \\
\text { improvement }\end{array}$ & Total \\
\hline $\begin{array}{l}\text { Physiological } \\
\text { solution }\end{array}$ & 10 & 3 & 13 \\
\hline $\begin{array}{l}\text { Dexamethasone } \\
4 \mathrm{mg}\end{array}$ & 8 & 5 & 13 \\
\hline Total & $\mathbf{1 8}$ & $\mathbf{8}$ & $\mathbf{2 6}$ \\
\hline
\end{tabular}

13 glands washed with physiological solution (76.92\%), and improvement of 8 of the 13 glands washed with dexamethasone (61.53\%). According to the McNemar test, this difference is not statistically significant $(p=0.4795)$. The Fisher exact test showed $p=0.6728$, which also determines that this difference is not statistically significant (see - Tables $\mathbf{1}$ and $\mathbf{2}$ ).

\section{Discussion}

The mechanical role of removing thick saliva, cellular debris, calculations, and, mainly, dilation of the ducts through sialendoscopy is fundamentally important in maintaining the current glandular function of affected patients. Current medications used in Sjögren syndrome do not adequately improve such symptoms. ${ }^{5,6}$ Sialendoscopy prevents inflammation and the resultant scarring from leading to obstruction at the exit of saliva, which, in turn, increases the risk for new inflammation and infection. In addition, it is advocated that a single procedure would bring benefit to salivary secretion, whereas little benefit would be achieved with several daily doses of medications and their side effects. ${ }^{5}$

The present study demonstrates the effectiveness of the sialendoscopy method in the act of mechanically dilating and removing ductal obstructive factors. For the population 
Table 2 Comparison of parotid scintigraphy results before and after sialendoscopy

\begin{tabular}{|l|l|l|l|l|l|l|l|l|l|l|}
\hline Patient & $\begin{array}{l}\text { Slope up } \\
\text { R Parotid } \\
\text { pre }\end{array}$ & $\begin{array}{l}\text { Slope down } \\
\text { R Parotid } \\
\text { pre }\end{array}$ & $\begin{array}{l}\text { Slope up } \\
\text { L Parotid } \\
\text { pre }\end{array}$ & $\begin{array}{l}\text { Slope down } \\
\text { L Parotid } \\
\text { E pre }\end{array}$ & $\begin{array}{l}\text { Slope up } \\
\text { R Parotid } \\
\text { post }\end{array}$ & $\begin{array}{l}\text { Slope down } \\
\text { R Parotid } \\
\text { post }\end{array}$ & $\begin{array}{l}\text { Slope up } \\
\text { L Parotid } \\
\text { post }\end{array}$ & $\begin{array}{l}\text { Slope down } \\
\text { L Parotid } \\
\text { post }\end{array}$ & $\begin{array}{l}\text { Improvement } \\
\text { R }\end{array}$ & $\begin{array}{l}\text { Improvement } \\
\text { L }\end{array}$ \\
\hline 1 & 0.0305 & -0.407 & 0.0197 & -0.207 & 0.0294 & -0.117 & 0.0171 & -0.246 & Yes & No \\
\hline 2 & 0.046 & -0.844 & 0.0563 & -0.622 & 0.0482 & -0.385 & 0.0407 & -0.33 & Yes & Yes \\
\hline 3 & 0.0849 & -2.02 & 0.0926 & -1.12 & 0.0119 & -0.939 & 0.0976 & -0.647 & Yes & Yes \\
\hline 4 & 0.0129 & -0.121 & 0.0112 & -0.0494 & 0.0163 & -0.206 & 0.0149 & -0.284 & No & No \\
\hline 5 & 0.00098 & -- & 0.00143 & -- & 0.00525 & --- & 0.000886 & -- & No & No \\
\hline 6 & 0.0522 & -0.0991 & 0.0655 & -0.652 & 0.0657 & -0.594 & 0.0503 & -0.624 & No & Yes \\
\hline 7 & 0.0106 & -0.0779 & 0.0166 & -0.128 & 0.0127 & -0.163 & 0.0225 & -0.258 & No & No \\
\hline 8 & --- & -- & -- & -- & 0.00453 & -0.00189 & 0.00549 & 0.000684 & Yes & Yes \\
\hline 9 & 0.0206 & -0.17 & 0.0165 & -0.0552 & 0.0232 & -0.1 & 0.0193 & -0.0472 & Yes & Yes \\
\hline 10 & 0.0114 & -0.0294 & 0.00965 & -0.0323 & -0.00005 & -0.0038 & 0.00106 & -0.00672 & Yes & Yes \\
\hline 11 & 0.0674 & -0.81 & 0.0651 & -0.489 & 0.00134 & -0.00549 & 0.0000871 & -0.00866 & Yes & Yes \\
\hline 12 & 0.0701 & -0.0951 & 0.0432 & -0.507 & -0.00488 & -0.00627 & -0.00625 & -0.00333 & Yes & Yes \\
\hline 13 & 0.0108 & -- & 0.0127 & -- & 0.0144 & -0.176 & 0.00701 & -0.0783 & Yes & Yes \\
\hline
\end{tabular}

Abbreviations: L, left; R, right.

studied-primary Sjögren syndrome-this result is a hope for treatment for the main consequence of their disease (dry mouth), thereby positively impacting overall quality of life. This study supports the few published studies regarding sialendoscopy and autoimmune diseases of the salivary glands, reinforcing the effectiveness of the method. 6,18

Sacham et $\mathrm{al}^{6}$ treated 10 patients with autoimmune diseases (Sjögren syndrome-without establishing primary or secondary; and systemic lupus erythematosus) with sialendoscopy. All patients recovered salivary function, with an average follow-up of 6 months (range, 5 months to 2 years). Kopec et $\mathrm{al}^{18}$ studied 51 patients with salivary duct strictures (without specifying causes) who underwent sialendoscopy. A 4-mg dexamethasone solution was used to flush the ducts. A significant improvement in salivation was achieved in $78 \%$ of patients (40/51).

In our study, there was no statistically significant difference $(p=0.4795)$ between ductal lavage with saline and dexamethasone. It is suggested that the importance of sialendoscopy itself goes beyond the importance of using a solution with dexamethasone through treatment of global stenosis, which prevents saliva flow in these patients. We hypothesized that use of dexamethasone could prevent inflammatory edema after sialendoscopy, and that it could contribute to the saliva output in this first analysis period of 1 month, even in a sample of 26 glands.

Additionally, in the separation of the group "washing with saline" versus "washing with dexamethasone," there was an improvement in 10 of the 13 glands with saline and 8 of the 13 glands with dexamethasone. It cannot be said that the serum would be less irritating because it is physiological and does not have other components that could be irritating to the ductal mucosa; however, future studies ought to investigate this hypothesis.

Our study, with the specification of parotid salivary duct strictures caused by primary Sjögren syndrome, supports improvement in salivation and consequently quality of life for these patients. Sialendoscopy is an important tool in the treatment of xerostomy symptoms caused by primary Sjogren syndrome. The procedure is very well tolerated by patients under local anesthesia. There is no major postprocedure. All patients were discharged shortly after the end of sialendoscopy and remained comfortable at home and in their daily activities.

The role of scintigraphy as an investigative method of salivary function is reaffirmed in this study. These data expand our knowledge of glandular activity. ${ }^{12,13}$ In this study, there were patients in whom initial examination showed glands with insufficient activity to form curves to be analyzed, but after the intervention with sialendoscopy, they presented formation of characteristic curves of glandular activity, even if discrete.

Scintigraphy provides an objective way to diagnose salivary function, as well as an important tool for monitoring this activity after interventions. It also provides, even in patients without symptoms related to salivary glands, the possibility of monitoring salivary function in patients undergoing iodotherapy after thyroid cancer and radiotherapy in patients with cancer in the head and neck region. ${ }^{12,13}$ Even in asymptomatic patients, scintigraphy is useful to check the damage caused after these interventions, as well as to monitor recovery. ${ }^{13}$

\section{Conclusion}

This study supports that sialendoscopy is as an important tool to improve salivary flow measured by scintigraphy of salivary glands in patients with primary Sjögren syndrome through dilation and resultant unblocking of the ducts. These data reaffirm the characteristic intraductal appearance of Sjögren syndrome of intense pallor of the mucosa and diffuse narrowing of the ducts. Moreover, it suggests that there is no statistically significant difference between saline and dexamethasone solutions for intraductal washing. 


\section{Conflict of Interests}

The authors have no conflict of interests to declare.

\section{References}

1 Humphrey SP, Williamson RT. A review of saliva: normal composition, flow, and function. J Prosthet Dent 2001;85(02): 162-169

2 Eveson JW. Xerostomia. Periodontol 2000 2008;48:85-91

3 He SL, Wang JH, Li M. Validation of the Chinese version of the Summated Xerostomia Inventory (SXI). Qual Life Res 2013;22 (10):2843-2847

4 Turner MD, Ship JA. Dry mouth and its effects on the oral health of elderly people. J Am Dent Assoc 2007;138:15S-20S

5 Fife RS, Chase WF, Dore RK, et al. . Cevimeline for the treatment of xerostomia in patients with Sjögren syndrome: a randomized trial. Arch Intern Med 2002;162(11):1293-1300

6 Shacham R, Puterman MB, Ohana N, Nahlieli O. Endoscopic treatment of salivary glands affected by autoimmune diseases. J Oral Maxillofac Surg 2011;69(02):476-481

7 Zenk J, Iro H, Klintworth N, Lell M. Diagnostic imaging in sialadenitis. Oral Maxillofac Surg Clin North Am 2009;21(03):275-292

8 Marchal F, Dulguerov P, Becker M, Barki G, Disant F, Lehmann W. Specificity of parotid sialendoscopy. Laryngoscope 2001;111(02): 264-271

9 Chossegros C, Guyot L, Richard O, Barki G, Marchal F. A technical improvement in sialendoscopy to enter the salivary ducts. Laryngoscope 2006;116(05):842-844
10 Martins-Carvalho C, Plouin-Gaudon I, Quenin S, et al. . Pediatric sialendoscopy: a 5-year experience at a single institution. Arch Otolaryngol Head Neck Surg 2010;136(01):33-36

11 Marchal F, Chossegros C, Faure FPublié Sous l'Egide de la Société Européenne des Glandes Salivaires. , et al; . [Salivary stones and stenosis. A comprehensive classification]. . [in French]Rev Stomatol Chir Maxillofac 2009;110(01):e1-e4

12 Vinagre F, Santos MJ, Prata A, da Silva JC, Santos AI. Assessment of salivary gland function in Sjögren's syndrome: the role of salivary gland scintigraphy. Autoimmun Rev 2009;8(08):672-676

13 Loutfi I, Nair MK, Ebrahim AK. Salivary gland scintigraphy: the use of semiquantitative analysis for uptake and clearance. J Nucl Med Technol 2003;31(02):81-85

14 Locker D. Dental status, xerostomia and the oral health-related quality of life of an elderly institutionalized population. Spec Care Dentist 2003;23(03):86-93

15 Dijkema T, Raaijmakers CP, Braam PM, Roesink JM, Monninkhof EM, Terhaard CH. Xerostomia: a day and night difference. Radiother Oncol 2012;104(02):219-223

16 Ferguson DB, Botchway CA. A comparison of circadian variation in the flow rate and composition of stimulated human parotid, submandibular and whole salivas from the same individuals. Arch Oral Biol 1980;25(8-9):559-568

17 Dawes C. Circadian rhythms in human salivary flow rate and composition. J Physiol 1972;220(03):529-545

18 Kopeć T, Szyfter W, Wierzbicka M, Nealis J. Stenoses of the salivary ducts-sialendoscopy based diagnosis and treatment. $\mathrm{Br}$ J Oral Maxillofac Surg 2013;51(07):e174-e177 